\title{
Current status of $5 \alpha$-reductase inhibitors in the management of lower urinary tract symptoms and BPH
}

\author{
Stavros Gravas • Matthias Oelke
}

Received: 16 October 2009 / Accepted: 17 November 2009 / Published online: 3 December 2009

(C) The Author(s) 2009. This article is published with open access at Springerlink.com

\begin{abstract}
Purpose Benign prostatic hyperplasia (BPH) is a progressive disease that is commonly associated with bothersome lower urinary tract symptoms (LUTS) and might result in complications, such as acute urinary retention and $\mathrm{BPH}-$ related surgery. Therefore, the goals of therapy for BPH are not only to improve LUTS in terms of symptoms and urinary flow, but also to identify those patients at a risk of unfavorable disease progression and to optimize their management. This article reviews the current status of therapy with $5 \alpha$-reductase inhibitors (5ARIs), namely fiasteride and dutasteride, for men with LUTS and BPH.

Method Data from key randomized controlled trials (Oxford level 1b) on the use of 5ARIs are analyzed.

Results The efficacy of 5ARIs either as monotherapy or in combination with $\alpha_{1}$-adrenoceptor antagonists in the management of LUTS and the impact of monotherapy and combined therapy on BPH progression are discussed. Further promises, including the withdrawal of the $\alpha$-blocker from the combined medical treatment and the potential clinical implications from the use of 5ARIs for prostate cancer chemoprevention in patients receiving 5ARIs for symptomatic $\mathrm{BPH}$ are highlighted.
\end{abstract}

S. Gravas $(\bowtie)$

Department of Urology, University of Thessaly,

6-8, Feidiou Street, 41221 Larissa, Greece

e-mail: sgravas2002@yahoo.com

M. Oelke

Department of Urology, Hannover Medical School,

Hannover, Germany

M. Oelke

Department of Urology, Academic Medical Centre,

University of Amsterdam, Amsterdam, The Netherlands
Conclusions Current evidence shows that 5ARIs are effective in treating LUTS and preventing disease progression and represent a recommended option in treatment guidelines for men who have moderate to severe LUTS and enlarged prostates.

Keywords Benign prostatic hyperplasia $\cdot$ Lower urinary tract symptoms $\cdot 5 \alpha$-Reductase inhibitors $\cdot$ Dutasteride . Finasteride $\cdot$ Combination treatment $\cdot$ Disease progression . Chemoprevention

\section{Introduction}

Lower urinary tract symptoms (LUTS) are very common in aging men and women. There is an increasing understanding that male LUTS result from several pathophysiological conditions, but benign prostatic hyperplasia (BPH) has been recognized as a major contributing factor for LUTS in aging men. It is also known that LUTS affect quality of life in the majority of those who reach average life expectancy [1]. In addition, longitudinal population-based studies which best analyse natural history of the disease have shown that $\mathrm{BPH}$ is a progressive disease. Progression includes increase of symptoms, acute urinary retention (AUR), and the need for BPH-related surgery $[1,2]$. Therefore, it becomes evident that BPH-LUTS has significant economical implications, since an increasing number of elderly men will eventually seek help for this condition. In daily practice, therapeutic approach is usually initiated with medical treatment and, if drugs fail, minimally invasive interventions or other surgical procedures will follow.

First-line pharmacologic treatment options for men with moderate to severe LUTS include the $\alpha_{1}$-adrenoceptor antagonist alfuzosin, doxazosin, tamsulosin, or terazosin and the $5 \alpha$-reductase inhibitor (5ARI) finasteride or 
dutasteride. This article focuses on the role of 5ARIs in the management of LUTS and disease progression.

\section{Mechanism of action}

Normal and abnormal growth of the prostate is dependent on the presence of hormones and growth factors. The androgen dihydrotestosterone (DHT) which is converted in the cell from its precursor testosterone by the enzyme $5 \alpha$-reductase, a nuclear-bound steroid enzyme localized primarily in prostatic stromal cells, is crucial in the initial development and normal growth of the prostate [3]. Two isoforms of 5ARIs have been identified: type 1 with minor expression and activity in the prostate, but predominant activity in extraprostatic tissues, such as skin or liver, and type 2 with predominant expression and activity in the prostate [4]. Both 5ARI isoenzymes are expressed in normal prostatic tissue, but overexpressed in BPH where they are responsible for the hyperplasia of stromal and epithelial cells in the transition zone and periurethral glands of the prostate that is associated with prostate gland enlargement, while in prostate cancer (PCa) cells 5AR1 expression is increased and 5AR2 expression is decreased compared with BPH tissue [5, 6]. Furthermore, both 5aR1 and 5aR2 are more prevalent in high-grade when compared with low-grade PCa [7]. 5ARIs act by apoptosis of prostatic epithelial cells, thereby reducing prostate size by an average of $15-25 \%$ over time $[5,8,9]$.

Although dutasteride and finasteride are both 5ARIs, their pharmacologic and clinical profiles are different. Table 1 displays the main characteristics of 5ARIs. Clark et al. directly compared the two 5ARIs and found that dutasteride achieved a greater reduction in serum DHT concentration (94.7\%) compared with finasteride (70.8\%) [10]. There is no direct comparative study with regard to intraprostatic DHT concentration, but the reported suppression appears to be slightly better for dutasteride than finasteride (94-97 vs. 85-91\%) [11].

Table 1 Key pharmacokinetic and pharmacodynamic characteristics of $5 \alpha$-reductase inhibitors

\begin{tabular}{lll}
\hline Parameters & Dutasteride & Finasteride \\
\hline $5 \alpha$-Reductase inhibition target & Type 1 and 2 & Type 2 \\
Metabolized in & Liver & Liver \\
Recommended daily dosage (mg) & $1 \times 0.5$ & $1 \times 5.0$ \\
Oral bioavailability (\%) & 60 & 80 \\
$T_{\max }(\mathrm{h})$ & $1-3$ & 2 \\
$\mathrm{~T}^{1 / 2}$ & $5 \mathrm{Weeks}$ & $6-8 \mathrm{~h}$ \\
Bound to plasma proteins (\%) & 99.5 & 90 \\
Serum DHT suppression $(\%)$ & 94.7 & 70.8 \\
\hline
\end{tabular}

$T_{\max }$ time of peak serum concentration, $T^{1 / 2}$ elimination half time, DHT dihydrotestosterone

\section{Efficacy in terms of International Prostate Symptom} Score (IPSS) and peak urinary flow rate $\left(Q_{\max }\right)$

\section{Monotherapy}

Finasteride is the most extensively studied 5ARI. Boyle et al. performed a meta-analysis of six randomized, placebo-controlled clinical trials [12]. The most significant finding was a positive correlation between mean baseline prostate volume and mean change in symptom score or $Q_{\max }$. Symptoms decreased by 1.8 points on the QuasiInternational Prostate Symptom Score (IPSS) Scale and $Q_{\max }$ increased by $0.9 \mathrm{ml} / \mathrm{s}$ in men with prostate volumes $<20 \mathrm{ml}$ compared with 2.8 points and $1.8 \mathrm{ml} / \mathrm{s}$ for men with prostate volumes $>60 \mathrm{ml}$ [12]. The difference between finasteride and placebo becomes significant for men, with a baseline prostate volume of $>40 \mathrm{ml}$. Following this meta-analysis, the outcomes of the 4-year Proscar Long-term Efficacy and Safety Study (PLESS) were released [13]. Finasteride reduced prostate volume by $18 \%$ compared with an increase of $14 \%$ with placebo, improved symptom scores (3.3 points vs. 1.3 for placebo) and increased $Q_{\max }(1.9$ vs. $0.2 \mathrm{ml} / \mathrm{s}$ for placebo) [13].

The combined analysis of the AUA-BPH Guidelines Panel found that finasteride leads to an IPSS improvement of 3.4 points at 12 months in both randomized placebocontrolled and open-label extension studies [14]. Symptom improvement is durable for up to 6 years in patients who maintained treatment. In addition, finasteride achieves a sustained $Q_{\max }$ improvement of approximately $2 \mathrm{ml} / \mathrm{s}$. In most trials, 5ARIs are slightly less effective than $\alpha$-blockers.

More recently, data from the monotherapy arm of the Medical Therapy of Prostatic Symptoms (MTOPS) study showed that prostate volume decreased by a median of $19 \%$ in patients receiving finasteride when compared with $24 \%$ increase in those receiving placebo [15]. Significant improvements over time in the IPSS and $Q_{\max }$ occurred in all monotherapy groups compared with the placebo group.

The clinical efficacy of dutasteride was evaluated in the three pivotal, 2-year, randomized, double-blind, placebocontrolled phase III trials [16]. Pooled analysis of these studies included 4,325 men and showed that dutasteride achieved a 4.5-point IPSS reduction resulting in a net difference of 2.2 points compared with placebo. $Q_{\max }$ improved significantly in the dutasteride group from 1 month, with an increase of $2.2 \mathrm{ml} / \mathrm{s}$ reported at 24 months (compared with 0.6 in the placebo group). A $26 \%$ reduction in prostate volume relative to placebo was found, with significant reductions from 1 month after treatment initiation and continuation until study end-point at 2 years. Following the completion of the blinded phase, 2,340 men entered the open-label, 24-months extension trial [17]. Dutasteride 
further reduced IPSS significantly; at the end of the 48month trial, IPSS was reduced by 6.5 points in men who received dutasteride during the entire study period and by 5.6 points in men who were initially treated with placebo and later with dutasteride. In contrast to previous findings with finasteride, there was no difference in the efficacy between prostate volumes 30-39 and $\geq 40 \mathrm{ml}$.

In a 12-month, randomized, comparative study, the Enlarged Prostate International Comparator Study (EPICS), 1,630 patients older than 50 years were randomized to dutasteride $(n=813)$ or finasteride $(n=817)$ [18]. After 1 year of treatment, prostate volume reduction from baseline was similar in both groups at $27.4 \%$. Improvements in IPSS (6.2 vs. 5.8) and $Q_{\max }(2.1$ vs. $1.8 \mathrm{ml} / \mathrm{s})$ were greater for dutasteride than finasteride, but not statistically significant.

\section{Combination therapy}

It is reasonable to assume that the combination of a 5ARI and $\alpha$-blocker, which have different and complementary modes of action, would potentially maximize treatment response. However, the first randomized, placebo-controlled trials with a follow-up $\leq 12$ months did not report superiority of combination treatment. Both the PRospective European DoxazosIn and Combination Therapy (PREDICT) trial (using doxazosin and/or finasteride) and the Veterans Affairs Cooperative Studies Benign Prostatic Hyperplasia Study (using terazosin and/or finasteride) showed that combination therapy was superior to 5ARI monotherapy, but failed to demonstrate a significant benefit over $\alpha$-blocker monotherapy [19, 20]. The MTOPS Study with a follow-up of $>4$ years was conducted to address the question of long-term benefit [15]. Although it was designed as a progression trial, MTOPS demonstrated that long-term combination therapy is superior to either $\alpha$-blocker or 5ARI monotherapy in improving LUTS and $Q_{\max }$. The 4year mean reduction in IPSS was 4.9, 6.6, 5.6, and 7.4 in the placebo, doxazosin, finasteride, and combination therapy groups, respectively. Similarly, the mean improvement in $Q_{\max }$ was $2.8,4.0,3.2$, and $5.1 \mathrm{ml} / \mathrm{s}$, respectively. IPSS decrease and $Q_{\max }$ increase in either active treatment was significantly better than placebo, doxazosin was significantly better than finasteride, and combination treatment was significantly better than either monotherapy.

The Combination of Avodart and Tamsulosin (CombAT) trial compared the efficacy of dutasteride and tamsulosin alone with the efficacy of combination therapy in men with larger prostates $(>30 \mathrm{ml})$ and higher serum PSA concentrations $(1.5-10 \mu \mathrm{g} / \mathrm{l})$ [21]. However, the trial did not have a placebo arm. In the pre-planned 2-year analysis, the combination treatment provided a significantly greater improvement in symptoms than either monotherapy alone [21]. At 2 years, the mean decrease from baseline IPSS was
6.2 with combination therapy, 4.9 with dutasteride, and 4.3 with tamsulosin. A statistically significant difference was achieved for combination therapy over dutasteride alone from month 3 and over tamsulosin alone from month 9. A combination therapy was also significantly more effective than either monotherapy in improving $Q_{\max }$ at month 6 throughout month 24. The adjusted mean $Q_{\max }$ increase in the combination group was $2.4 \mathrm{ml} / \mathrm{s}$ and significantly greater than for dutasteride and tamsulosin $(1.9$ and $0.9 \mathrm{ml} /$ $\mathrm{s}$, respectively). The adjusted mean decrease from baseline prostate volume was $26.9 \%$ in the combination therapy group and $28.0 \%$ in the dutasteride group but unchanged for tamsulosin-treated patients.

Post hoc analyses of 2-year data from the CombAT study provided useful insights into the impact of several baseline parameters on changes of IPSS and $Q_{\max }$ [22]. It was found that combination therapy was more effective than tamsulosin or dutasteride monotherapy alone in improving IPSS and $Q_{\max }$ after 2 years regardless of baseline parameters [22]. When compared with tamsulosin, dutasteride showed greater IPSS improvement in certain subgroups, most notably in those men with values higher than the median: IPSS $>16$, prostate volume $>49 \mathrm{ml}$, PSA $>3.5 \mu \mathrm{g} / \mathrm{l}$, and IPSS-QoL score $\geq 4$. In addition, dutasteride alone or in combination was associated with significantly greater improvements in $Q_{\max }$ compared with tamsulosin.

The 4-year data of the CombAT study has been published recently [23]. For patients who completed the study period, mean change in IPSS from baseline to year 4 was significantly higher for the combination therapy compared with tamsulosin or dutasteride alone $(-7.3,-4.9,-6.4$, respectively). Decrease in IPSS-QoL score was significantly greater for the combination treatment $(-1.5)$ compared with tamsulosin $(-1.1)$ or dutasteride $(-1.3)$. $Q_{\max }$ improvement was significantly higher for combination treatment $(2.4 \mathrm{ml} / \mathrm{s})$ compared with tamsulosin $(0.7 \mathrm{ml} / \mathrm{s})$ or dutasteride $(2 \mathrm{ml} / \mathrm{s})$. There was a tendency towards a continuous decrease in IPSS and continuous increase in $Q_{\max }$ for dutasteride monotherapy and combination treatment over time, whereas both parameters worsened again during tamsulosin treatment after 15-18 months. Interestingly, postvoid residual urine significantly decreased in the treatment arms containing dutasteride, but not with tamsulosin alone. Table 2 displays the key RCTs with 5ARIs.

\section{Efficacy in terms of disease progression}

\section{Monotherapy}

The goal of BPH therapy is not only to improve LUTS, but also prevent disease progression. Analysis of the placebo 
Table 2 Key randomized trials with $5 \alpha$-reductase inhibitors in men with benign prostatic enlargement and LUTS

\begin{tabular}{|c|c|c|c|c|c|c|c|c|c|}
\hline Trial & $\begin{array}{l}\text { Duration } \\
\text { (month) }\end{array}$ & $\begin{array}{l}\text { Treatment } \\
\text { arms }\end{array}$ & $\begin{array}{l}\text { Patients } \\
(n)\end{array}$ & $\begin{array}{l}\text { Symptom } \\
\text { change } \\
\text { (IPSS) }\end{array}$ & $\begin{array}{l}Q_{\max } \text { change } \\
(\mathrm{ml} / \mathrm{s})\end{array}$ & $\begin{array}{l}\text { Change } \\
\text { PV (\%) }\end{array}$ & $\begin{array}{l}\text { BPH-surgery } \\
\text { RR }(\%)\end{array}$ & $\begin{array}{l}\text { AUR } \\
\text { RR }(\%)\end{array}$ & $\begin{array}{l}\text { Oxford } \\
\text { level of } \\
\text { evidence } \\
(1 \mathrm{a}-5)\end{array}$ \\
\hline \multirow[t]{2}{*}{ Andersen et al. $[24]^{\mathrm{a}}$} & \multirow[t]{2}{*}{24} & Placebo & 2,109 & & & & & & \multirow[t]{2}{*}{$1 \mathrm{~b}$} \\
\hline & & Finasteride & 2,113 & NA & NA & NA & $-34^{\mathrm{c}}$ & $-57^{\mathrm{c}}$ & \\
\hline \multirow[t]{2}{*}{ McConnell et al. [13] } & \multirow[t]{2}{*}{48} & Placebo & 1,503 & -1.3 & +0.2 & +14.0 & & & \multirow[t]{2}{*}{$1 \mathrm{~b}$} \\
\hline & & Finasteride & 1,513 & $-3.3^{\mathrm{c}}$ & $+1.9^{\mathrm{c}}$ & $-18.0^{\mathrm{c}}$ & $-55^{\mathrm{c}}$ & $-57^{\mathrm{c}}$ & \\
\hline \multirow[t]{4}{*}{ McConnell et al. [15] ${ }^{\mathrm{b}}$} & \multirow[t]{4}{*}{54} & Placebo & 737 & -4.0 & 1.4 & +24.0 & & & \multirow[t]{4}{*}{$1 \mathrm{~b}$} \\
\hline & & Doxazosin & 756 & $-6.0^{\mathrm{c}}$ & $2.5^{\mathrm{c}}$ & +24.0 & -3 & -35 & \\
\hline & & Finasteride & 768 & $-5.0^{\mathrm{c}}$ & $2.2^{\mathrm{c}}$ & $-19.0^{\mathrm{c}, \mathrm{d}}$ & $-64^{\mathrm{c}, \mathrm{d}}$ & $-68^{\mathrm{c}, \mathrm{d}}$ & \\
\hline & & Combination & 786 & $-7.0^{\mathrm{c}, \mathrm{d}, \mathrm{e}}$ & $3.7^{\mathrm{c}, \mathrm{d}, \mathrm{e}}$ & $-19.0^{\mathrm{c}, \mathrm{d}}$ & $-67^{\mathrm{c}, \mathrm{d}}$ & $-81^{\mathrm{c}, \mathrm{d}}$ & \\
\hline \multirow[t]{2}{*}{ Roehrborn et al. [16] $]^{a}$} & \multirow[t]{2}{*}{24} & Placebo & 2,158 & -2.3 & 0.6 & +1.5 & & & \multirow[t]{2}{*}{$1 \mathrm{~b}$} \\
\hline & & Dutasteride & 2,167 & $-4.5^{\mathrm{c}}$ & $2.2^{\mathrm{c}}$ & $-25.7^{\mathrm{c}}$ & $-48^{c}$ & $-57^{\mathrm{c}}$ & \\
\hline \multirow[t]{3}{*}{ Roehrborn et al. [21] } & \multirow[t]{3}{*}{24} & Tamsulosin & 1,611 & -4.3 & 0.9 & 0.0 & & & \multirow[t]{3}{*}{$1 \mathrm{~b}$} \\
\hline & & Dutasteride & 1,623 & -4.9 & 1.9 & -28.0 & NA & NA & \\
\hline & & Combination & 1,610 & $-6.2^{\mathrm{d}, \mathrm{e}}$ & $2.4^{\mathrm{d}, \mathrm{e}}$ & $-26.9^{d}$ & NA & NA & \\
\hline \multirow[t]{3}{*}{ Roehrborn et al. [23] } & \multirow[t]{3}{*}{48} & Tamsulosin & 1,611 & -3.8 & 0.7 & +4.6 & & & \multirow[t]{3}{*}{$1 \mathrm{~b}$} \\
\hline & & Dutasteride & 1,623 & -5.3 & 2.0 & $-28.0^{\mathrm{d}}$ & $-31.1^{\mathrm{d}}$ & $-18.3^{\mathrm{d}}$ & \\
\hline & & Combination & 1,610 & $-6.3^{\mathrm{d}, \mathrm{e}}$ & $2.4^{\mathrm{d}, \mathrm{e}}$ & $-27.3^{\mathrm{d}}$ & $-70.6^{\mathrm{d}}$ & $-67.6^{\mathrm{d}}$ & \\
\hline
\end{tabular}

$Q_{\text {max }}$ maximum urinary flow rate, $P V$ prostate volume, $A U R$ acute urinary retention, $R R$ risk reduction vs. placebo, $N A$ not assessed

${ }^{\text {a }}$ Pooled data

b Median values

c Significant compared with placebo

d Significant compared with $\alpha$-blocker

e Significant compared with $5 \alpha$-reductase inhibitor

arm (737 men) of the MTOPS study showed that the rate of overall clinical progression of BPH events in the placebo group was 4.5 per 100 person-years, for a cumulative incidence of $17 \%$ among men who had follow-up data of at least 4 years [15]. Several risks factors at baseline were identified for disease progression, such as prostate volume $\geq 31 \mathrm{ml}, \quad$ PSA concentration $\geq 1.6 \mu \mathrm{g} / \mathrm{l}, \quad Q_{\max } \leq$ $10.6 \mathrm{ml} / \mathrm{s}$, postvoid residual volume $\geq 39 \mathrm{ml}$, and age $\geq$ 62 years. Risk reduction is mediated through decrease in prostate volume and possibly through decrease in bladder outlet resistance. In the PLESS study after 4 years, finasteride treatment reduced the relative risk of AUR by $57 \%$ (AUR occurred in $7 \%$ of men receiving placebo and $3 \%$ receiving finasteride) and surgery by 55\% (10\% of men receiving placebo and 5\% receiving finasteride) [13]. In the MTOPS study, a significant reduction in the risk of overall clinical progression (defined as IPSS increase $\geq 4$ points, AUR, urinary incontinence, renal insufficiency, or recurrent urinary tract infections) by $34 \%$ in the finasteride arm compared with placebo (to 2.9 per 100 person-years) was shown [15]. An earlier pooled analysis of randomized trials with 2-year follow-up data clearly indicated that the treatment with finasteride significantly decreased the occurrence of AUR by $57 \%$ and surgical intervention by $34 \%$ with an overall 35\% reduction in the two BPH-related endpoints relative to placebo in patients with moderately symptomatic BPH [24].

Dutasteride has also demonstrated efficacy in reducing the risks for AUR and BPH-related surgery. Pooled phase III studies have shown a reduced relative risk of AUR $(57 \%)$ and a surgical intervention (48\%) compared with placebo at 2 years [16]. In addition, this reduction was maintained to 4 years during the open-label phase of the study [23, 25].

\section{Combination therapy}

The impact of combination treatment on BPH progression has also been evaluated from the MTOPS trial that included 3,047 men treated for an average of 4.5 years. This landmark study showed that the risk of long-term clinical progression (primarily due to increasing IPSS) was reduced by $66 \%$ with combined therapy (vs. placebo) and to a greater extent than with either finasteride or doxazosin monotherapy (34 and 39\%, respectively) [15]. When only the risks of AUR and need for BPH-related surgery over the 4-year 
study were analyzed, finasteride, alone or in combination, but not doxazosin significantly reduced both risks. Rates of AUR were 0.2 events $/ 100$ person-years in the finasteride group, 0.1 events/100 person-years in the combination therapy group, 0.4 events $/ 100$ person-years in the doxazosin group, and 0.6 events $/ 100$ person-years in the placebo group. In terms of risk for invasive BPH therapy, the placebo group experienced 1.3 events/100 person-years compared to 0.5 events $/ 100$ person-years with finasteride, 0.4 events/100 person-years with combination therapy, and 1.3 events/100 person-years with doxazosin. Subsequent analysis of the MTOPS data concluded that men with prostate volumes of $25 \mathrm{ml}$ or more have a greater benefit from combination therapy in terms of reducing risk of long-term clinical progression compared with either monotherapy [26].

In the CombAT trial, entry thresholds for prostate volume $(\geq 30 \mathrm{ml})$ and PSA serum concentration $(\geq 1.5 \mu \mathrm{g} / \mathrm{l})$ have been used to select patients with higher risk of disease progression [21]. The predefined 4-year primary endpoints were reduction in the risks of AUR and BPH-related surgery [23]. BPH overall disease progression (defined as symptom deterioration $\geq 4$ IPSS points, AUR, incontinence, recurrent urinary tract infections, or renal insufficiency) appeared after 4 years in $12.6 \%$ of patients with the combination of dutasteride and tamsulosin, but in $17.8 \%$ with dutasteride, and in $21.5 \%$ with tamsulosin. The reduction in the relative risk of overall disease progression was significantly greater for the combination treatment $(-31.2 \%$ compared to dutasteride and $-44.1 \%$ compared to tamsulo$\sin )$. When compared with tamsulosin, combination therapy reduced the relative risks of AUR by $67.8 \%$, BPH-related surgery by $70.6 \%$ and symptom deterioration by $41.3 \%$ after 4 years.

\section{Discontinuation therapy}

5ARIs need several months to develop clinical efficacy, whereas $\alpha$-blockers act within hours or a couple of days; therefore, many clinicians initially use $\alpha$-blockers for fast symptom relief until efficacy of 5ARIs is achieved. The randomized, double-blind, placebo-controlled Symptom Management After Reducing Therapy (SMART) trial evaluated the combination of tamsulosin with dutasteride and the impact of tamsulosin discontinuation after 6 months [27]. After discontinuation of the $\alpha$-blocker, almost three quarters of patients reported no worsening of symptoms. However, patients with severe symptoms (IPSS $\geq 20$ ) at baseline may benefit from longer combination therapy.

A recent prospective open-label multicentre trial evaluated the equivalence of the efficacy and safety of combination therapy (finasteride plus $\alpha$-blocker) for 9 months, followed by monotherapy with finasteride alone for 3 or
9 months [28]. Equivalence was defined as mean difference of $\leq 2$ IPSS points between the end of the combination period and the end of each monotherapy period. LUTS improvement after combination therapy was sustained for 3 months (IPSS difference 1.24) and 9 months (IPSS difference -0.44$)$ with a similar safety profile. The main limitations of such studies include the short duration of the combination therapy and the short follow-up period.

In a retrospective study using a large managed care member database, the likelihood of $\alpha$-blocker discontinuation was evaluated over a 12-month period in 1,674 patients aged $\geq 65$ years receiving $\alpha$-blockers in combination therapy with either dutasteride or finasteride [29]. Dutasteride patients discontinued $\alpha$-blocker therapy $64 \%$ faster than finasteride patients at any time point. At 12 months, $62 \%$ of patients were treated with dutasteride alone compared to $43.7 \%$ of men treated with finasteride alone. Despite its limitations regarding the retrospective nature and the subjective decision of $\alpha$-blocker cessation, this study has shown a difference in rate and timing in favor of dutasteride which may have clinical implications requiring further examination.

\section{Safety-adverse events}

5ARIs are well tolerated and have only minimal side effects. The most common adverse events (AE) are sexual dysfunction including, reduced libido, erectile dysfunction and, less frequently, ejaculation disorders which occur more frequently in recipients with 5ARIs than with placebo $[5,9]$. Gynecomastia appears in approximately $1-2 \%$ of patients. The new onset of most drug-related AEs usually arises within the first year of treatment, and new-onset $\mathrm{AE}$ rates after the first year are often similar to those among patients receiving placebo. It seems that drug-related sexual dysfunction do not represent a clinically significant cause of treatment withdrawal $[5,9]$.

It has also been reported that dutasteride and finasteride have a similar safety profile. In a 1-year comparative trial in men who received either dutasteride $(n=813)$ or finasteride $(n=817)$, the incidence of impotence ( 7 vs. $8 \%)$, decreased libido (5 vs. $6 \%$ ), ejaculation disorders (1\% in both groups), gynecomastia (1\% in both groups), headache (1\% in both groups), and malaise/fatigue (1\% in both groups) did not differ significantly [30]. In both COMBAT and MTOPS, drug-related AEs were more frequent during combination treatment than for either monotherapy $[15,21,23]$.

\section{ARIs and PSA}

Serum PSA concentration is used as a proxy parameter for prostate volume and marker for PCa. In most clinical 
guidelines, PSA evaluation is recommended during initial evaluation of patients with LUTS [14, 31]. A higher PSA value is a good predictor for the risk of AUR and need for surgery in men with BPH-LUTS [15, 32].

Dihydrotestosterone, the predominant factor of exocrine secretion of prostatic epithelial cells, is the main source of intraprostatic and serum PSA. The use of 5ARIs results in serum PSA decrease of about $50 \%$ after 6-12 months [33, 34]. Therefore, PSA concentration has to be doubled for counseling and clinical decision making in men receiving 5ARIs. Marks et al. performed an extensive review of available studies and concluded that doubling of serum PSA concentration in men who have received 5ARIs for up to 6-9 months overestimated actual PSA, whereas correctly estimated actual PSA concentration during 1-3 years of treatment and underestimating it thereafter [34]. It was proposed that a PSA increase $\geq 0.3 \mu \mathrm{g} / \mathrm{l}$ from a nadir should be used as an additional biopsy trigger in men receiving a 5ARIs for BPH; these men should also be followed-up on a regular base.

\section{ARIs and chemoprevention}

There is an increasing interest in the use of 5ARIs for PCa chemoprevention. The American Society of Clinical Oncology (ASCO) and American Urological Association Practice Guidelines Committee jointly convened a panel of experts to develop evidence-based recommendations [35]. Although this issue is beyond the scope of this article, some findings may have clinical implications in patients receiving 5ARIs for symptomatic BPH. Data from the Prostate Cancer Prevention Trial (PCPT), currently the only completed randomized $\mathrm{PCa}$ risk reduction trial, showed a $24.8 \%$ reduction in $\mathrm{PCa}$ prevalence during the 7 -year period between the finasteride (18.4\%) and the placebo group (24.4\%) [36]. However, a higher incidence of high-grade cancers (Gleason scores 7-10) was found in the finasteride arm (37 vs. $22.2 \%$ for placebo). Several potential explanations have been proposed and the majority of the panel members judged that the higher incidence of high-grade tumors is likely due to confounding factors than to an actual increase in aggressive cancers [35]. However, men taking 5ARIs for the management of BPH-LUTS may also benefit from chemoprevention. In such cases, observed benefits must be weighed against theoretical harm in men who are being treated for symptomatic or bothersome conditions. New information are eagerly expected from the REduction by DUtasteride of prostate Cancer Events (REDUCE) trial, an ongoing 4-year, multicentre, randomized, double-blind, placebo-controlled study aiming at the evaluation of the efficacy and safety of oral dutasteride $0.5 \mathrm{mg} /$ day in $\mathrm{PCa}$ risk reduction [37].

\section{Conclusions}

Current evidence shows that monotherapy with 5ARIs is effective in men with BPH-LUTS and benign prostatic enlargement by altering the underlying disease process; in addition, 5ARIs provide the long-term benefit of risk reduction for disease progression. For this reason, both the European and the American Urological Association Guidelines recommend 5ARIs in the management of patients with LUTS associated with demonstrable prostatic enlargement $[14,31]$. The MTOPS study demonstrated the long-term superiority of combination treatment to either monotherapy with regard to both symptom reduction and disease progression, while the analysis of the CombAT study, for the first time, has shown benefit in improving symptoms and $Q_{\max }$ for combination therapy over monotherapies during the first 12 months of treatment, thereby reinforcing the position of 5ARIs in the management of patients with BPH-LUTS.

Conflict of interest statement The authors declare that they have no conflict of interest.

Open Access This article is distributed under the terms of the Creative Commons Attribution Noncommercial License which permits any noncommercial use, distribution, and reproduction in any medium, provided the original author(s) and source are credited.

\section{References}

1. Fitzpatrick JM (2006) The natural history of benign prostatic hyperplasia. BJU Int 97(Suppl 2):3-6

2. Emberton M, Cornel EB, Bassi PF et al (2008) Benign prostatic hyperplasia as a progressive disease: a guide to the risk factors and options for medical management. Int J Clin Pract 62:1076-1086

3. Carson C III, Rittmaster R (2003) The role of dihydrotestosterone in benign prostatic hyperplasia. Urology 61(4 Suppl 1):2-7

4. Iehlé C, Délos S, Guirou O et al (1995) Human prostatic steroid 5 alpha-reductase isoforms-a comparative study of selective inhibitors. J Steroid Biochem Mol Biol 54:273-279

5. Keam SJ, Scott LJ (2008) Dutasteride: a review of its use in the management of prostate disorders. Drugs 68:463-485

6. Thomas LN, Lazier CB, Gupta R et al (2005) Differential alterations in 5alpha-reductase type 1 and type 2 levels during development and progression of prostate cancer. Prostate 63:231-239

7. Thomas LN, Douglas RC, Lazier CB et al (2008) Type 1 and Type 2 5a-reductase expression in the development and progression of prostate Cancer. Eur Urol 53:244-252

8. Rittmaster RS, Norman RW, Thomas LN, Rowden G (1996) Evidence for atrophy and apoptosis in the prostates of men given finasteride. J Clin Endocrinol Metab 81:814-819

9. Smith AB, Carson CC (2009) Finasteride in the treatment of patients with benign prostatic hyperplasia: a review. Ther Clin Risk Manag 5:535-545

10. Clark RV, Hermann DJ, Cunningham GR et al (2004) Marked suppression of dihydrotestosterone in men with benign prostatic hyperplasia by dutasteride, a dual 5alpha-reductase inhibitor. J Clin Endocrinol Metab 89:2179-2184 
11. Montorsi F, Alcaraz A, Desgrandchamps F et al (2009) A broader role for 5ARIs in prostate disease? Existing evidence and emerging benefits. Prostate 69:895-907

12. Boyle P, Gould AL, Roehrborn CG (1996) Prostate volume predicts outcome of treatment of benign prostatic hyperplasia with finasteride: meta-analysis of randomized clinical trials. Urology 48:398-405

13. McConnell JD, Bruskewitz R, Walsh P et al (1998) The effect of finasteride on the risk of acute urinary retention and the need for surgical treatment among men with benign prostatic hyperplasia. Finasteride Long-Term Efficacy and Safety Study Group. N Engl J Med 338:557-563

14. AUA Practice Guidelines Committee (2003) AUA guideline on management of benign prostatic hyperplasia (2003). Chapter 1: diagnosis and treatment recommendations. J Urol 170:530-547

15. McConnell JD, Roehrborn CG, Bautista OM et al (2003) The long-term effect of doxazosin, finasteride, and combination therapy on the clinical progression of benign prostatic hyperplasia. $\mathrm{N}$ Engl J Med 349:2387-2398

16. Roehrborn CG, Boyle P, Nickel JC et al, ARIA3001 ARIA3002 and ARIA3003 Study Investigators (2002) Efficacy and safety of a dual inhibitor of 5-alpha-reductase types 1 and 2 (dutasteride) in men with benign prostatic hyperplasia. Urology 60:434-441

17. Roehrborn CG, Lukkarinen O, Mark S et al (2005) Long-term sustained improvement in symptoms of benign prostatic hyperplasia with the dual 5alpha-reductase inhibitor dutasteride: results of 4-year studies. BJU Int 96:572-577

18. Gilling P, Jacobi G, Tammela T et al (2005) Efficacy of dutasteride and finasteride for the treatment of benign prostate hyperplasia: results of the 1-year Enlarged Prostate International Comparator Study (EPICS). BJU Int 95(Suppl 1):1-38 abstract U051

19. Kirby RS, Roehrborn C, Boyle P et al (2003) Efficacy and tolerability of doxazosin and finasteride, alone or in combination, in treatment of symptomatic benign prostatic hyperplasia: the Prospective European Doxazosin and Combination Therapy (PREDICT) trial. Urology 61:119-126

20. Lepor H, Williford WO, Barry MJ et al (1996) The efficacy of terazosin, finasteride, or both in benign prostatic hyperplasia. Veterans Affairs Cooperative Studies Benign Prostatic Hyperplasia Study Group. N Engl J Med 335:533-539

21. Roehrborn CG, Siami P, Barkin J et al (2008) The effects of dutasteride, tamsulosin and combination therapy on lower urinary tract symptoms in men with benign prostatic hyperplasia and prostatic enlargement: 2-year results from the CombAT study. J Urol 179:616-621

22. Roehrborn CG, Siami P, Barkin J et al (2009) The influence of baseline parameters on changes in international prostate symptom score with dutasteride, tamsulosin, and combination therapy among men with symptomatic benign prostatic hyperplasia and an enlarged prostate: 2-year data from the CombAT study. Eur Urol 55:461-471

23. Roehrborn CG, Siami P, Barkin J et al (2009) The effects of combination therapy with dutasteride and tamsulosin on clinical outcomes in men with symptomatic benign prostatic hyperplasia: 4-year results from the CombAT study. Eur Urol. doi:10.1016/ j.eururo.2009.09.035
24. Andersen JT, Nickel JC, Marshall VR et al (1997) Finasteride significantly reduces acute urinary retention and need for surgery in patients with symptomatic benign prostatic hyperplasia. Urology 49:839-845

25. Gittelman M, Ramsdell J, Young J, McNicholas T (2006) Dutasteride improves objective and subjective disease measures in men with benign prostatic hyperplasia and modest or severe prostate enlargement. J Urol 176:1045-1050

26. Kaplan SA, McConnell JD, Roehrborn CG, Medical Therapy of Prostatic Symptoms (MTOPS) Research Group et al (2006) Combination therapy with doxazosin and finasteride for benign prostatic hyperplasia in patients with lower urinary tract symptoms and a baseline total prostate volume of $25 \mathrm{ml}$ or greater. J Urol $175: 217-220$

27. Barkin J, Guimarães M, Jacobi G et al (2003) Alpha-blocker therapy can be withdrawn in the majority of men following initial combination therapy with the dual 5alpha-reductase inhibitor dutasteride. Eur Urol 44:461-466

28. Nickel JC, Barkin J, Koch C et al (2008) Finasteride monotherapy maintains stable lower urinary tract symptoms in men with benign prostatic hyperplasia following cessation of alpha blockers. Can Urol Assoc J 2:16-21

29. Issa MM, Lin PJ, Eaddy MT et al (2008) Comparative analysis of alpha-blocker utilization in combination with 5-alpha reductase inhibitors for enlarged prostate in a managed care setting among Medicare-aged men. Am J Manag Care 14(5 Suppl 2):S160-S166

30. Andriole GL, Kirby R (2003) Safety and tolerability of the dual 5alpha-reductase inhibitor dutasteride in the treatment of benign prostatic hyperplasia. Eur Urol 44:82-88

31. de la Rosette J, Alivizatos G, Madersbacher S et al (2004) EAU guidelines on benign prostatic hyperplasia (BPH). http://www. uroweb.org

32. Roehrborn CG (2006) Alfuzosin $10 \mathrm{mg}$ once daily prevents overall clinical progression of benign prostatic hyperplasia but not acute urinary retention: results of a 2-year placebo-controlled study. BJU Int 97:734-741

33. Guess HA, Gormley GJ, Stoner E, Oesterling JE (1996) The effect of finasteride on prostate specific antigen: review of available data. J Urol 155:3-9

34. Marks LS, Andriole GL, Fitzpatrick JM et al (2006) The interpretation of serum prostate specific antigen in men receiving $5 \alpha$-reductase inhibitors: a review and clinical recommendations. J Urol 176:868-874

35. Kramer BS, Hagerty KL, Justman S et al (2009) Use of $5 \alpha$-reductase inhibitors for prostate cancer chemoprevention: American Society of Clinical Oncology/American Urological Association 2008 Clinical Practice Guideline. J Urol 181:1642-1657

36. Thompson IM, Goodman PJ, Tangen CM et al (2003) The influence of finasteride on the development of prostate cancer. N Engl J Med 349:215-224

37. Andriole G, Bostwick D, Brawley O et al (2004) Chemoprevention of prostate cancer in men at high risk: rationale and design of the reduction by dutasteride of prostate cancer events (REDUCE) trial. J Urol 172:1314-1317 